\section{Bent spine syndrome}

\author{
G Serratrice, J Pouget, J F Pellissier
}

\begin{tabular}{|c|c|}
\hline \multirow{2}{*}{$\begin{array}{l}\text { Cliniques des Maladies } \\
\text { du Système Nerveux et } \\
\text { de l'Appareil } \\
\text { Locomoteur } \\
\text { G Serratrice } \\
\text { J Pouget }\end{array}$} & Eight similar cases are reported, one in detail. \\
\hline & $\begin{array}{l}\text { Table } 1 \text { Secondary forms of paraspinal muscle weakness } \\
\text { and wasting }\end{array}$ \\
\hline $\begin{array}{l}\text { Laboratoire } \\
\text { d'Anatomie } \\
\text { Pathologique et de } \\
\text { Neuropathologie, CHU } \\
\text { la Timone, 13005 } \\
\text { Marseille, France } \\
\text { J F Pellissier }\end{array}$ & $\begin{array}{l}\text { Spine disorders } \\
\text { Ankylosing spondylitis } \\
\text { Movement disorders } \\
\text { Parkinson's disease } \\
\text { Spasmodic torticollis } \\
\text { Torsion spasm } \\
\text { Neuromuscular diseases } \\
\text { Myasthenia gravis (some cases) } \\
\text { Limb girdle dystrophy }\end{array}$ \\
\hline $\begin{array}{l}\text { Correspondence to: } \\
\text { Professor G Serratrice, } \\
\text { Clinique des Maladies de } \\
\text { Systeme Nerveux et de } \\
\text { l'Appareil Locomoteur, } \\
\text { CHU la Timone, } 13005 \\
\text { Marseille, France. }\end{array}$ & $\begin{array}{l}\text { Extensive facioscapulohumeral dystrophy } \\
\text { Amyotrophic lateral sclerosis (proximal forms) } \\
\text { Progressive spinal atrophy } \\
\text { Dermatomyositis } \\
\text { Metabolic diseases } \\
\text { Pompe disease } \\
\text { Carnitine deficiency }\end{array}$ \\
\hline $\begin{array}{l}\text { Received } 2 \text { June } 1995 \\
\text { and in revised form } \\
7 \text { September } 1995\end{array}$ & $\begin{array}{l}\text { Psychiatric } \\
\text { Camptocormia } \\
\text { Hysterical } \\
\text { Manic depressive disease }\end{array}$ \\
\hline
\end{tabular}

CASE 1

A 65 year old man had experienced a bent posture for six years on walking. At 65 he walked stooping forward and used a walking stick. Examination in erect posture (fig 1) showed a bent spine with no possibility of trunk extension but a moderate neck extension. In the supine position the abnormal posture disappeared. However, procumbent spine extension was impossible. Paraspinal muscles were atrophic. Neurological examination was normal, particularly tonus and reflexes. Radiographs showed a slight osteophytosis. Serum creatine kinase was 245 IU/1 (normal 130). Muscle CT showed hypodensity of the paraspinal muscles (fig 2), but the muscles had normal outline. Myelography and CSF were normal. In paraspinal muscles, EMG showed a full pattern activity with normal motor unit potentials. An EMG was normal in the lower limbs as were nerve conduction velocities. A muscle biopsy of the left quadriceps showed variations in fibre size and a few hypertrophic fibres, internal nuclei, and fibre splitting. Some ragged red fibres were seen with modified Gomori staining. Oxidative enzymes showed slight architectural changes. Some fibres were cytochrome oxidase negative.

There was a loss of complex I (13\% of mean control values) and III (23\% of mean control values). The patient was treated with coenzyme Q10 (200 mg/day) for 10 months without any improvement.

At 66 years of age CT showed no changes in paraspinal muscle hypodensity. An EMG recorded some spontaneous activity in the paraspinal muscles. In the quadriceps muscles EMG was myopathic. At the age of $68 \mathrm{CT}$ was the same, but coronal MRI (fig 2) showed a rarefaction of the paravertebral muscle fibres compared with controls. At 69 the bent posture was aggravated. A paraspinal muscle biopsy showed extensive fibrosis associated with fatty infiltration and only some scattered muscle fibres. Table 2 gives pertinent data for patients 2-8.

\section{Discussion}

At a late adult age, the eight patients (table 2) developed an abnormal stooping posture in the erect position and on walking. Patients were old adults (mean age 60.6 ; three women, five men). The patients' occupations did not seem relevant (three housewives, one man retired from the French railway company SNCF, one clerk, one turner, two labourers). In two cases there was a family history.

Trunk extension was impossible on account 
Figure 1 Patient 1: bent posture, attempted neck extension.

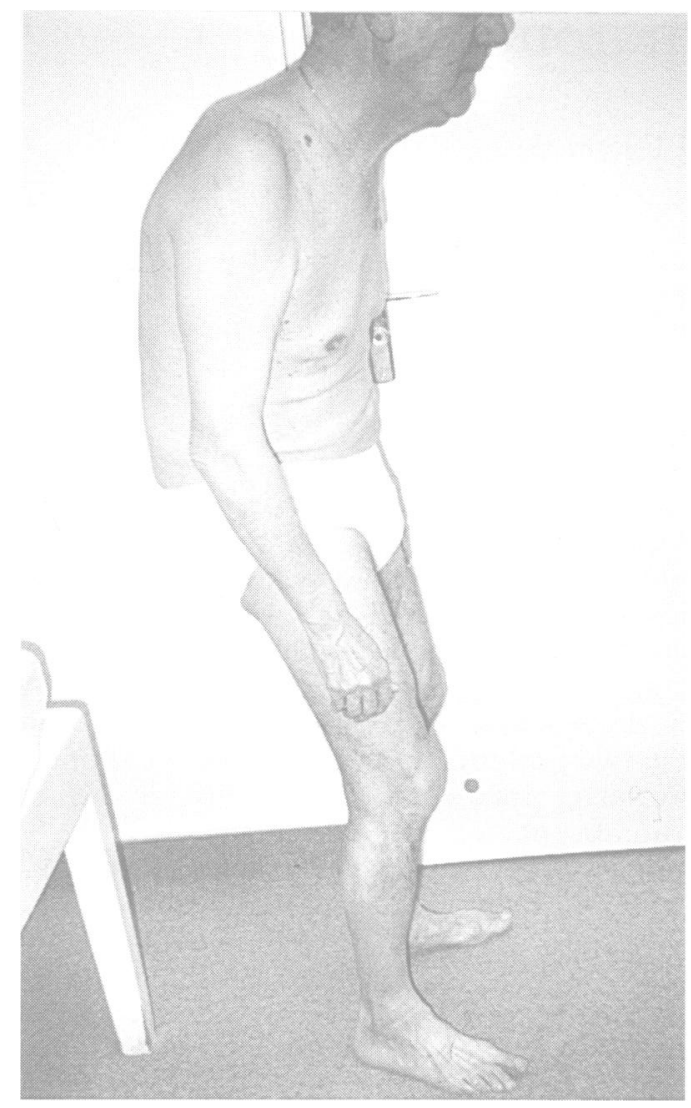

of the weakness of the paraspinal muscles. The disease can be differentiated from kyphosis as the problem disappeared in the supine position and the passive extension of the trunk was normal. In some patients the bent posture was exaggerated by several factors-for example, walking up a slope, and sexual intercourse. Low back pain was reported in some cases at the onset. It was transitory and disappeared in the course of the disease. The neurological examination was normal, especially tonus, reflexes, and sensory functions. The concentration of serum creatine kinase was moderately increased in two patients. Paraspinal muscle EMG and muscle biopsy showed nonspecific or slight abnormalities suggesting a myopathic disorder (five patients) rather than a neuropathic one. Radiographs did not show any abnormalities in any patient. Muscle CT showed hypodensity of the paraspinal muscles in all patients. To summarise, these eight patients are characterised by two features: clinically progressive weakness of paravertebral muscles and paraspinal muscle hypodensity on CT.

Similar cases are rare. The "bent back of soldiers" was noted during the first world war ${ }^{2}$ but was considered as hysterical. Other cases of psychiatric origin have been published $^{3}$ under the term of camptocormia. These cases quoted as camptocormia are different from the secondary kyphosis seen in various diseases: dystonias, Parkinson's disease, progressive spinal atrophy, and others in which specific clinical features allow the differential diagnosis (table 1). Primary cases of camptocormia have occasionally been reported with non-specific abnormalities in paraspinal muscles, which were sometimes inflammatory or necrotic. " An ultrastructural study ${ }^{5}$ did not produce significant findings. Fibrosis was constant" but there was no evidence of a true dystrophic muscle disease. In another study devoted to paravertebral muscles in diseases of the cervical spine, ${ }^{10}$ biopsies were performed on 10 patients during surgical procedures and yielded abnormal findings in all cases, with neurogenic atrophy or type II fibre atrophy. Ragged red fibres were frequent, nemaline rods were conspicuous in one case, for which paraspinal myopathy was suggested. There was no bent spine posture but the myopathy could contribute to the vertebral shifting. Examination by CT was not performed.

Clinical study of the paravertebral muscles, which play the main part in posture and gait, is poorly documented. Essentially, their function is the extension of the spine in reaction to gravity and body weight, especially the abdominal mass. If they are too weak, the bent spine posture is increased by the viscera weight.

There are different paraspinal muscles. The short spinal muscles, also called multifidus, are deep and immediately posterior to the transverse process. They are innervated by the corresponding posterior rami; EMG of these muscles is performed with a deep needle insertion, laterally to the spinous process, towards the transverse process. Conversely, in the long spinal muscles - the longissimus dorsi, which are superficial and internal-EMG is performed by inserting a needle 2 to $3 \mathrm{~cm}$ laterally to the spinous process. Examination by EMG is sometimes difficult in the absence of complete relaxation. Motor unit potentials have a reduced amplitude and short duration and can be mistaken for fibrillation potentials. In our patients the results of EMG of paraspinal muscles were not homogeneous, myopathic in most cases, neuropathic or normal in others.

Likewise, serum muscular enzyme study was not conclusive. Serum creatine kinase concentration tended to be high sometimes but was not so in all patients. The most useful investigation was $\mathrm{CT}$, which showed similar results in all patients. Paraspinal muscle outline was normal, sometimes slightly flattened. Hypodensity of the muscles was always noted. Muscles seemed empty, with a loss of substance, but their volume was usually preserved. This aspect is not specific. Paravertebral muscle hypodensity is not unusual, especially in limb girdle dystrophy, even in facioscapulohumeral dystrophy. In such cases, however, a bent spine posture has never been noted. Moreover CT was abnormal in the limbs, showing a myopathic pattern with quadriceps muscle hypodensity by contrast with normal density or hyperdensity in gracilis and sartorius muscle. Coronal MRI, performed in two patients, is also of interest, particularly in comparison to controls, showing the totality of paravertebral muscles and a striking rarefaction of muscles fasciculi.

Paraspinal muscle biopsy is theoretically the 
Figure 2 Patient $1(A)$ CT. Left: patient, hypodensity of paraspinal muscle. Right: normal 67 year old man. (B) Coronal $M R I$. Left: patient, pronounced rarefaction of paravertebral muscle fibres. Right: normal 64 year old man.
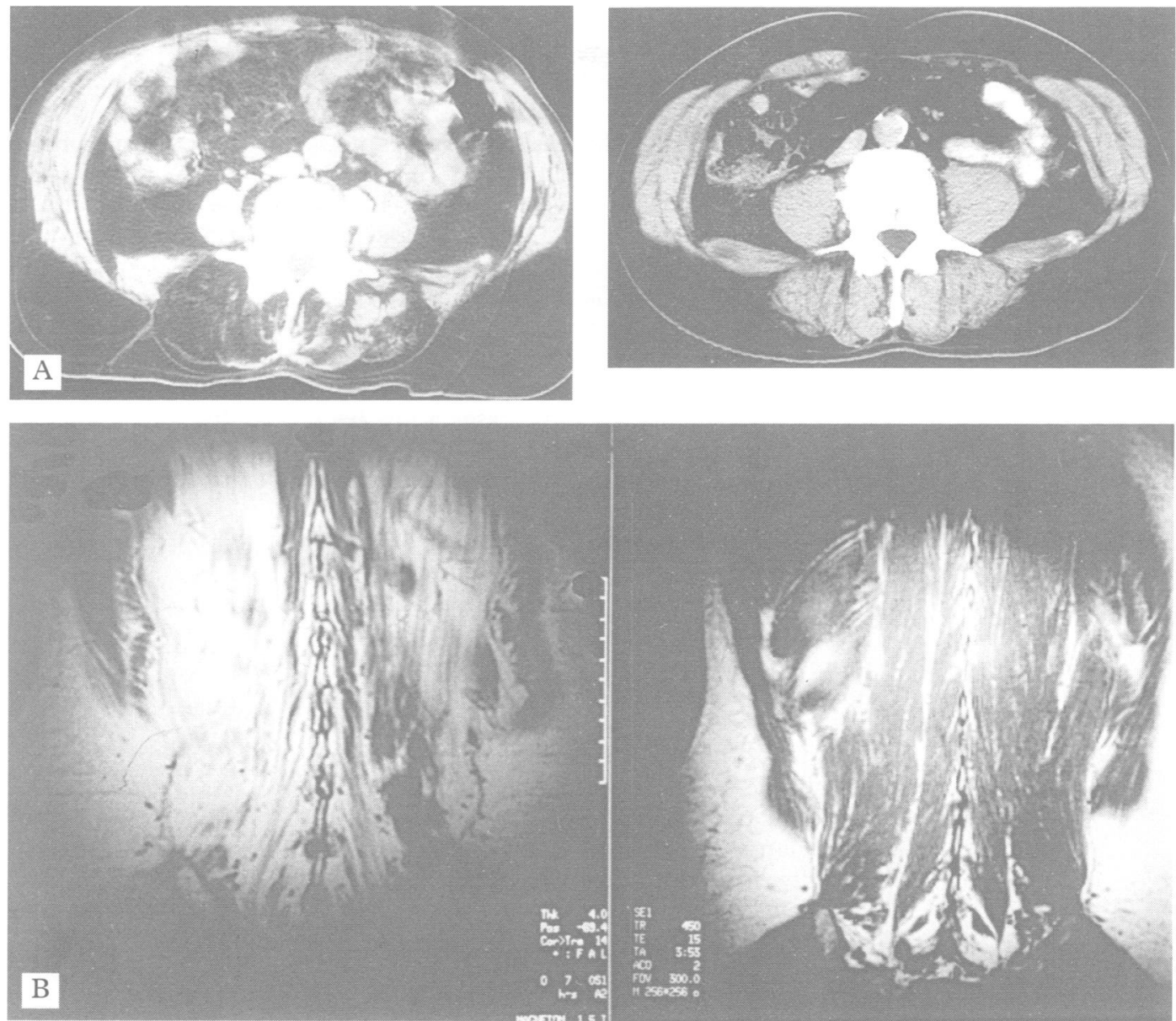

most informative procedure. However, the technique is sometimes difficult. Because of the amount of muscle fibrosis and fatty infiltration, the sample of muscle is often too small. Often, abnormalities without apparent relevance are observed. For example, ragged red fibres, as noted in patients 1,5 , and 8 , are not infrequent in normal elderly subjects and are probably, therefore, age related. Mitochondrial myopathy was only a possibility in patient 1 , in whom there was a complex I and III deficiency. Inflammatory changes are epiphenomena and do not assess a focal myositis. In the paravertebral muscle biopsies performed in four patients fibrosis and fatty

infiltration (two patients), type II fibre atrophy with AMP deaminase deficiency (one patient), variations in fibre size with angulated fibres, necrosis and regeneration, and lymphocytic inflammation (one patient) were observed. The most striking feature was a finger print aspect in an ultrastructural study (case 5). In seven other patients a limb muscle (quadriceps or deltoid muscles) biopsy was performed. The results were not homogeneous: there were variations in fibre size, type II fibre atrophy, ragged red fibres, necrosis, and regeneration. However, the pattern was myopathic.

The reason for the bent posture is undoubtedly a weakness of the paraspinal muscles, as

Table 2 Eight cases of bent spine syndrome

\begin{tabular}{|c|c|c|c|c|c|c|c|}
\hline Sex & $\begin{array}{l}\text { Age } \\
(y)\end{array}$ & $\begin{array}{l}\text { Onset } \\
(y)\end{array}$ & $\begin{array}{l}\text { Family } \\
\text { history }\end{array}$ & $\begin{array}{l}\text { Serum } \\
\text { creatine } \\
\text { kinase (IUIl) }\end{array}$ & $E M G$ & $\begin{array}{l}\text { Limb } \\
\text { muscle biopsy }\end{array}$ & $\begin{array}{l}\text { Paraspinal } \\
\text { muscle } \\
\text { biopsy }\end{array}$ \\
\hline$M$ & 65 & 59 & 0 & 245 & Myopathic & Myopathic & Fibrosis \\
\hline$M$ & 63 & 61 & 0 & 54 & Normal & $\begin{array}{l}\text { Type II atrophy } \\
\text { Normal AMP d }\end{array}$ & $\begin{array}{l}\text { Myopathic } \\
\text { Type II atrophy } \\
\text { AMP d deficiency }\end{array}$ \\
\hline F & 66 & 63 & $\begin{array}{l}\text { Mother } \\
\text { and sister }\end{array}$ & 100 & Myopathic & Type II atrophy & NP \\
\hline $\begin{array}{l}M \\
M\end{array}$ & $\begin{array}{l}79 \\
75\end{array}$ & $\begin{array}{l}75 \\
72\end{array}$ & $\begin{array}{l}0 \\
0\end{array}$ & 630 & $\begin{array}{l}\text { Myopathic } \\
\text { Myopathic } \\
\text { and } \\
\text { neuropathic }\end{array}$ & $\begin{array}{l}\text { Myopathic } \\
\text { Type I predominance }\end{array}$ & $\begin{array}{l}\text { NP } \\
\text { Fingerprint } \\
\text { Myopathic } \\
\text { Inflammatory with } \\
\text { lymphocytes } \\
\text { Ragged red fibres }\end{array}$ \\
\hline $\begin{array}{l}M \\
\mathrm{~F}\end{array}$ & $\begin{array}{l}50 \\
69\end{array}$ & $\begin{array}{l}49 \\
68\end{array}$ & $\begin{array}{l}0 \\
\text { Mother }\end{array}$ & $\begin{array}{r}164 \\
26\end{array}$ & $\begin{array}{l}\text { Normal } \\
\text { Myopathic }\end{array}$ & $\begin{array}{l}\text { Myopathic } \\
\text { NP }\end{array}$ & $\begin{array}{l}\text { Fibrosis (two biopsies) } \\
\text { NP }\end{array}$ \\
\hline $\mathbf{F}$ & 61 & 55 & 0 & 169 & Myopathic & $\begin{array}{l}\text { Myopathic } \\
\text { Ragged red fibres } \\
\text { COX negative fibres }\end{array}$ & NP \\
\hline
\end{tabular}

$\mathrm{M}=$ male; $\mathrm{F}=$ female; $\mathrm{AMP} \mathrm{d}=\mathrm{AMP}$ deaminase $\mathrm{NP}=$ not performed COX = cytochrome oxidase. 
shown by CT and MRI. It is difficult to conclude that there is paravertebral muscle dystrophy in the absence of more significant pathological changes. Muscle biopsy shows sometimes extensive fibrosis, sometimes nonspecific changes. Are they the result of an early dystrophic pathological aspect in old adults? Are histopathological changes secondary to the posture? These questions are difficult to answer. On the other hand there are some data in favour of a late restricted axial myopathy. Firstly a secondary paraspinal amyotrophy is unlikely. No associated signs were found in any of our patients. In some cases a low back pain was reported at the onset of the syndrome. It is unlikely, however, that the pain is the triggering factor of the bent spine syndrome, considering the frequency of lower back pain. Moreover in one case, with a focal inflammatory pain at the onset, the syndrome persisted even in the absence of pain. It is more probable that the low back pain at the onset of the disease is of mechanical origin and secondary to the development of paraspinal muscle weakness. Secondly, despite poorly conclusive EMG and muscle biopsy results, the CT pattern was constantly myopathic, with fatty muscles and preserved outline. Thirdly, in the progressive course, there were correlations between the clinical weakness, the loss of muscle displayed on CT, and the fibrosis and fatty infiltration in muscle biopsy. Finally, there were two hereditary cases: patient 3, a woman, had an afflicted mother (aged 92 with the same bent posture since the age of 65) and a 69 year old sister. Patient 7, also a woman, had an afflicted 82 year old mother. A question remains as to why the onset is late in life. A hypothesis could be a late form of congenital myopathy. In case 5 for example, the muscle biopsy showed a paraspinal fingerprint aspect with a predominance of type I fibres restricted to paraspinal muscles. Late forms of congenital myopathy are not unusual but never seen in paraspinal muscles.

In conclusion, although a myopathic origin for this disease seems probable, before evoking a paraspinal muscle dystrophy ${ }^{11}$ further research is necessary to determine the mechanism, especially a genetic study in familial cases. Despite non-specific results from muscle biopsy, our eight patients have a strikingly similar clinical picture with a common CT pattern. Therefore, this syndrome seems to be a distinct clinical entity characterised by a progressive paraspinal muscle weakness in old adults, and a characteristic posture. We suggest these cases could be classified as having "bent spine syndrome".

We are grateful to the Association Française contre la Myopathie who partially supported this study.

1 Souques A, Rosanoff-Saloff. La camptocormie-Incurvation du tronc consecutive aux traumatismes du dos et des ombes. Considérations morphologiques. Rev Neurol (Paris) 1915;22:937-9.

2 Hurst AF. The bent back of soldiers. BMF 1918;2:621-3.

3 Gomez EA, Drooby AS. Camptocormia in a case of manic depressive disorder. Psychosomatics 1987;28:592-5.

4 Laroche M, Delisle MB, Mazieres B, Rascol A, Cantagrel A, Arlet $\mathrm{Ph}$. Myopathie tardive localisée aux muscles A, Arlet Ph. Myopathie tardive localisee aux muscles Rhum Mal Osteoartic 1991;58:829-38.

5 Hilliquin $P$, Menkès CJ, Laoussadi S, Job-Deslandre C, Serratrice G. Camptocormie du sujet âgé. Rev Rhum 1992;59:169-75.

6 Poullin P, Daumen-Legré V, Serratrice G. Camptocormie du sujet âgé: myopathie ou dystonie musculaire. Rev Rhum Mal Osteoartic 1993;60:159-61.

7 Brégeon Ch, Bavant C, Masson Ch, Audran M, Corcos J, Rénier JC. Cyphose lombaire réductible du sujet âge: notre expérience à partir de 14 observations. Synoviale 1993;19:12-7.

8 Delisle MB, Laroche M, Dupont H, Rochaix P, Rumeau JL. Morphological analysis of para-spinal muscles: comparison of progressive lumbar kyphosis (camptocormia) and narrowing of lumbar canal disk protrusions. and narrowing of lumbar canal

9 Laroche M, Delisle MB. La camptocormie est-elle une myopathie paravertébrale? Rev Rhum Mal Osteoartic myopathie para

10 Anderson JR, Pickard JD, Chau KK. The paravertebral muscle in disease of the cervical spine: histochemical morphometric and electron microscopic study. Muscle Nerve 1994(suppl 1), S22-1-8:254.

11 Serratrice G, Murayama N, Azulay J Ph, Pouget J, Rasco A, Salamon G. Contribution of CT scan in diagnosis of neuromuscular disease. Muscle Nerve 1994;(suppl 1), W $28-1: 67$ 